
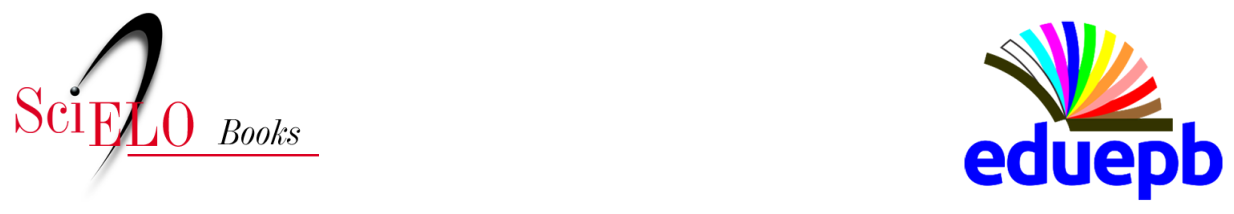

\title{
O Gênero Curta Metragem como Objeto de Ensino e Aprendizagem da Leitura e da Produção Textual
}

\author{
Jeane dos Santos \\ Roseane B. Feitosa Nicolau
}

\section{SciELO Books / SciELO Livros / SciELO Libros}

SANTOS. J, and NICOLAU, R. B. F. O Gênero Curta Metragem como Objeto de Ensino e Aprendizagem da Leitura e da Produção Textual. In: ARANHA, S. D. G., and SOUZA, F. M., eds. Práticas de ensino e tecnologias digitais [online]. Campina Grande: EDUEPB, 2018, pp. 181-212. Ensino e aprendizagem collection, vol. 3. ISBN: 978-85-78795-26-9. http://doi.org/10.7476/9786586221657.0008.

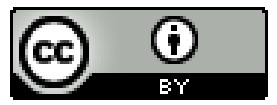

All the contents of this work, except where otherwise noted, is licensed under a Creative Commons Attribution 4.0 International license.

Todo o conteúdo deste trabalho, exceto quando houver ressalva, é publicado sob a licença Creative Commons Atribição 4.0.

Todo el contenido de esta obra, excepto donde se indique lo contrario, está bajo licencia de la licencia Creative Commons Reconocimento 4.0. 


\title{
O GÊNERO CURTA METRAGEM COMO OBJETO DE ENSINO E APRENDIZAGEM DA LEITURA E DA PRODUÇÃO TEXTUAL
}

\author{
Jeane dos Santos ${ }^{1}$ \\ Roseane B. Feitosa Nicolau ${ }^{2}$
}

\section{Introdução}

A inserção de recursos audiovisuais no contexto educacional não é novidade, como afirma a autora do livro Educação, imagem e mídias, Costa (2013). De modo que, no início do século $X X$, documentários de curta e média metragem eram utilizados como apoio às práticas educativas. Entretanto, no contexto das aulas de língua portuguesa, ainda é incipiente essa inserção dos vídeos como apoio às práticas educativas e ao ensino da língua, uma vez que os métodos e estratégias de leitura e de escrita

1 Formada em Letras pela UEPB (2007), especialista em Literatura e Cultura Afro-Brasileira e Africana também pela UEPB (2011), mestra em Letras pela UFPB (2018). Atua como professora de Língua Portuguesa na Rede Municipal de Jacaraú-PB e de Duas Estradas-PB. (enaejsantos@hotmail.com )

2 Graduada em Letras (Português e Francês), Mestra em Letras (2002) e Doutora em Linguística (2008) pela UFPB. Professora da UFPB do Curso de Letras do Campus IV, do PROFLETRAS (Programa de Mestrado Profissional em Letras ) e do MPLE (Mestrado Profissional em Linguística e Ensino). (rosenicolau. ufpb@gmail.com) 
contemplam o conceito limitado de texto linear e a imagem ainda é vista como suporte ilustrativo do texto escrito, como uma representação sem merecer interpretações, compreensão e interação.

Uma ferramenta importantíssima de apoio ao professor, que acredita no potencial de vídeos de curta-metragem e que deseja inseri-los no ambiente escolar, é o portal Curta na Escola. No entanto, não basta dispor os vídeos no ambiente escolar, seja de forma física ou virtual. É preciso que o professor esteja preparado, ou pelo menos queira estar, para utilizá-lo de forma criativa e responsável, para a promoção da aprendizagem. É no tocante a este ponto - a ação do professor - que se apresenta a nossa proposta, a qual propõe o trabalho em sala de aula com curtas-metragens como objeto de ensino e de aprendizagem em aulas de língua portuguesa, especificamente com turma dos últimos anos do Ensino Fundamental.

A partir da exploração do curta-metragem (gênero multimodal), esperamos que os alunos adquiram a capacidade de compreensão do modo como os textos, nas novas tecnologias, operam e utilizem o que foi aprendido, significando, por meio da leitura, e ressignificando, por meio da escrita, para realizar, assim, uma prática transformadora na qual se tornam agentes letrados.

Acreditamos que o estudo da linguagem cinematográfica pode se mostrar bastante produtivo na tarefa de capacitar os alunos a lidarem com o texto multimodal, inserindo-os, portanto, no multiletramento. Ao introduzir o curta-metragem no currículo, a escola assume como uma de suas funções sociais pensar o cinema para além do entretenimento, como um elemento social e cultural de modo reflexivo e crítico. E isso implica reconhecer o poder 
informacional e formador dessa linguagem, capaz de proporcionar a assimilação e a compreensão de certas ideias, valores e conceitos que seriam difíceis de outra forma; assim, reforçamos o caráter pedagógico do curta.

A partir dessa abordagem multimodal da linguagem, por meio do curta, faz-se mister uma concepção de letramento que dê conta dessa dinamicidade da linguagem e, para isso, propomos um trabalho de leitura e de escrita sob a ótica do multiletramento.

Devemos salientar que, ao escolher utilizar os curtas como objeto de ensino e de aprendizagem da leitura e da escrita em sala de aula, baseamo-nos na Base Nacional Comum Curricular (doravante BNCC), que entrou em vigor em 2017 e norteará a elaboração de currículos, quando postula, ao tratar do estudo da língua, que
o componente Língua Portuguesa cabe, então, proporcionar aos estu- dantes experiências que contribuam para a ampliação dos letramentos, de forma a possibilitar a participação significativa e crítica nas diversas práticas sociais permeadas/constitu- ídas pela oralidade, pela escrita e por outras linguagens (BRASIL, 2017, p. 65-66, grifo dos autores).

Essa escolha ainda teve apoio nas ideias de Moran (2005, p. 36), quando afirma que a

educação escolar precisa compreender e incorporar mais as novas linguagens, desvendar os seus códigos, 
dominar as possibilidades de expressão e as possíveis manipulações. É importante educar para usos democráticos, mais progressistas e participativos das tecnologias que facilitem a educação dos indivíduos.

Além disso, há um gama de produções midiáticas que poderiam servir a essa educação democrática, que considera as múltiplas linguagens levando o aluno a constituir-se como sujeito linguisticamente competente. Entre essas produções estão os curtas-metragens. Assim, ao falar sobre as potencialidades educacionais dos meios eletrônicos

[é] premente que se instaure o debate, a implantação de políticas e estratégias para o desenvolvimento e disseminação de propostas de trabalho inovadoras utilizando os meios eletrônicos de informação e comunicação, já que eles possuem um enorme potencial educativo para complementar e aperfeiçoar o processo de ensino e aprendizagem (BRASIL, 1998a, p. 142).

Logo, cabe ao professor planejar, implementar e orientar as atividades didáticas de modo que o trabalho com curtas, possam fazer parte das atividades das aulas de língua portuguesa, consoante com Conceitos e Procedimentos Subjacentes às Práticas de Linguagem dos PCN (BRASIL, 1998b). Vemos os conteúdos e significações 
dos curtas como modos de perceber a realidade, de aprender, de produzir e de difundir conhecimentos, informações e ideologias.

Para isso, selecionamos o curta Selfie com o gato ${ }^{3}$, uma produção estrangeira que aborda um tema atual, apresentando questões sociais reais, vivenciadas pelos jovens; e partimos para a proposta de ensino e aprendizagem da leitura e da produção textual, a partir de curtas-metragens, apresentando como objetivos teórico-metodológicos: construir uma concepção de curta-metragem como elemento de ensino e aprendizagem, defendendo sua viabilidade como recurso pedagógico multimodal; e, efetivar a aplicação da linguagem cinematográfica e a narrativa de curta-metragem no ensino, desenvolvendo um trabatho de leitura e de escrita de curta, levando em conta os elementos multimodais para a construção do sentido do texto.

Comecemos, então, pela construção uma da concepção de curta-metragem, sua composição, estrutura e, por fim, sua aplicação no ensino.

\section{Curta-metragem: conceito e aplicação no ensino}

O curta-metragem, ou curta na linguagem informal, é um termo vindo do francês court-métrage, refere-se a um filme de curta duração que dura trinta minutos ou menos. Segundo o Dicionário Houaiss (2009, p. 588), que ratifica essa duração máxima de trinta minutos, ele possui "intenção estética, informativa, educacional ou

3 Título original: Selfie cat (tradução nossa) 
publicitária, ger. exibido como complemento de um programa cinematográfico".

O surgimento do curta-metragem tem como marco o nascimento do cinema no final do século XIX, quando os irmãos Auguste e Louis Jean Lumière, filhos do fotógrafo Antoine Lumière, fizeram a primeira exibição em público em 28 de dezembro de 1895, no Grand Café, localizado na capital francesa. Esses primeiros filmes apresentavam entre quarenta e cinquenta segundos e, com a ampliação desse tempo, chegou-se à duração de setenta minutos, em 1906, com o primeiro longa-metragem do cinema mundial The Story of the Kelly Gang ${ }^{4}$, de origem australiana.

Como explica Alcântara (2014, o conceito de curta-metragem era associado "a uma limitação técnica. Dessa forma, a produção de curtas não era uma questão de escolha de seus produtores; ao contrário, tratava-se da única forma possível de realização cinematográfica naquele momento embrionário das produções cinematográficas".

Por conseguinte, para diferenciar esses vídeos de tamanhos variados, houve a necessidade da adjetivação, ou seja, começou-se a diferenciar o filme "curto" (short film) do filme (film), isto é, do filme "longo" (feature film), ou melhor, o curta-metragem do longa-metragem. Porém, ambos integram a Sétima Arte - o cinema.

No entanto, podemos afirmar que os filmes, inseridos na categoria de curta têm se adaptado às mudanças contemporâneas. Por exemplo, com a explosão das redes, não é novidade que os usuários compartilhem vídeos cada vez menores, muitos dos quais não ultrapassam 15 segundos.

4 A História da Gangue Kelly (tradução nossa). 
Estrutura do curta: narrativa e elementos cinematográficos

Ao tratar dos filmes de curtas-metragens, os estudiosos franceses Vanoye e Goliot-Lété (2014, p. 110) afirmam que eles "exibem seus dispositivos (narrativos ou discursivos), sua estrutura dramática e rítmica, a forma-sentido que produz seu impacto de maneira mais evidente que os longas-metragens". E explicam que isso acontece porque possivelmente não há tempo para esses elementos serem apreendidos, de modo que essa exibição acontece de forma "rápida, aguda, como se 'precipitassem".

Ribeiro (2013) afirma que, devido a esse curto tempo de duração, os curtas-metragens apresentam as seguintes características:

reduzido número de personagens e diálogos; condensação narrativa [...]; tempo da história, na maioria dos casos, linear; guiões verossímeis; grande carga emotiva e sugestiva e final, geralmente, surpreendente; pela sua natureza cinematográfica, veicula conteúdos culturais, socioculturais, transmite valores educativos e traduz-se numa rentável fonte para trabalhar aspectos interculturais (RIBEIRO, 2013, p. 21-22).

Isso significa que a dinamicidade desse tipo de narrativa multimodal apenas agrega valores e ratifica a importância de sua utilização no ambiente escolar, bem como a sua viabilidade. Ou seja, valores são agregados, a partir da possibilidade de contar histórias, mesmo com poucas 
personagens e quase nenhum diálogo, mas com roteiros capazes de aflorar as emoções e sensibilidades de nossos alunos. A sua importância deve-se à necessidade de preparar os nossos discentes para atribuírem sentidos aos textos multimodais que envolvam temáticas socioculturais, valores educativos, enfim, que sejam relevantes para a vida em sociedade.

Ainda, quanto à celeridade do filme de metragem curta, Alex Moletta (2009, p. 17) equipara-o "ao conto na literatura ou ao haicai na poesia", ou seja, a história narrada deve ser breve e impactante, mesmo sendo dramática ou cômica não deve haver tempo nem espaço para discursos vazios. Portanto, "a precisão, a coerência, a densidade e a unidade de ação" são as principais características desse formato de cinema.

Logo, o realizador do curta-metragem precisa selecionar imagens que narrem o que acontece; que elas, além de estarem de acordo com o que foi proposto, revelem os conflitos a serem solucionados, apresentando ligação direta com o tema ou conflito principal, como explica o autor. Ele ainda esclarece "que cinema é a arte da imagem e não do diálogo" (MOLETTA, 2009, p. 18), isto significa que é preciso utilizar a imagem de forma narrativa.

Sobre essa arte, Costa (2013, p. 95) lembra que após as pinturas parietais da pré-história, a pintura e o desenho também enfrentaram o desafio de "imprimir graficamente a ideia do tempo, do movimento e da narratividade". Portanto, com o surgimento e a difusão da indústria cinematográfica, além de entretenimento, o cinema tornou-se "um meio mágico de se contar histórias" (COSTA, 2013, p. 99). 
Nesse sentido, o cerne do cinema é a imagem em movimento. Essa imagem pode ser narrada com diferentes planos; o movimento pode ser panorâmico, travelling ou resultante destes dois; o ângulo da câmera pode ser horizontal, alto ou baixo; a imagem pode ser acompanhada da linguagem verbal escrita e/ou falada. Convém ressaltar que todos esses recursos foram descobertos paulatinamente, às vezes de maneira até acidental.

Segundo Jean-Claude Bernardet (2004, p. 33), "a criação de estruturas narrativas e a relação com o espaço" foram dois elementos essenciais dessa gramática cinematográfica, e o autor cita a diferença entre a produção norte-americana e a alemã. A primeira estava preocupada com uma linguagem transparente, isto é, uma narrativa que priorizava o enredo, as emoções dos personagens, de modo que a atenção do espectador se voltasse para o que é narrado como um fragmento da realidade, sem provocar estranhamento.

É possível compreender melhor a estrutura de um audiovisual por meio de análises, pois, como afirmam Vanoye e Goliot-Lété (2014), analisar um filme implica descrever os elementos constitutivos deste para em seguida reconstruí-lo ${ }^{5}$. Ou seja, é preciso individualizar cada elemento para, em seguida, estabelecer conexões, atribuir sentidos.

5 Os autores esclarecem que analisar um filme "significa duas coisas: a atividade de analisar [...]; e também pode significar o resultado dessa atividade[.]" (VANOYE; GOLIOT-LÉTÉ, 2014, p. 14). Neste trabalho, nosso propósito é tratarmos da primeira, isto é, a atividade de análise. 
Portanto, decompor as partes de um filme significa:

despedaçar, descosturar, desunir, extrair, separar, destacar e denominar materiais que não se percebem isoladamente "a olho nu", uma vez que o filme é tomado pela totalidade. Parte-se, portanto, do texto fílmico para "desconstruí-lo" e obter um conjunto de elementos distintos do próprio filme (VANOYE; GOLIOTLÉTÉ, 2014, p. 14-15).

Logo, esse processo de decomposição da estrutura de uma obra cinematográfica é sucedido pela etapa de recomposição:

Uma segunda fase consiste, em seguida, em estabelecer elos entre esses elementos isolados, em compreender como eles se associam e se tornam cúmplices para fazer surgir um todo significante: reconstruir o filme [...]. É evidente que essa reconstrução não apresenta qualquer ponto em comum com a realização concreta do filme (VANOYE; GOLIOT-LÉTÉ, 2014, p. 15).

Esses autores alertam para processos completamente distintos: o processo criativo de elaboração do filme e o estudo deste por outros. Pois, como lembra Mesquita (2006), a "organização" de um enredo e o(s) sentido(s) que 
o texto guarda variam em cada época e geram diferentes significações.

A partir deste momento, passamos a descrever alguns desses elementos incorporados a obras audiovisuais. Para isso, recorremos à obra Como analisar narrativas, de Gancho (2014), que descreve os elementos de uma narrativa de maneira didática. Assim, apresentamos os principais componentes de uma narrativa:

a) Enredo. Corresponde ao encadeado de ações executadas ou a executar pelas personagens, a fim de criar sentido ou emoção no espectador. Gancho (2014) expõe alguns nomes correspondentes ao conjunto dos fatos de uma história, a exemplo de fábula, intriga, ação, trama. Em seguida, apresenta o elemento estruturador das partes, isto é, o conflito que, por sua vez, de forma geral determina a introdução, o desenvolvimento, o clímax e o desfecho da história.

b) Personagens. Elemento integrante da narrativa, a personagem é um ser sempre fictício que só existe se participa ativamente do desenvolvimento do enredo. Não importa se é humano, objeto ou qualquer outro ser, desde que aja na narrativa. Quanto ao papel da personagem no desenvolvimento do enredo, esta pode ser protagonista ou antagonista, caso tenha desempenho principal. Independente de serem mais ou menos participativos, esses seres podem ser planos, apresentam características fixas, ou redondos, quando há uma complexidade maior na atuação e possuem uma variedade maior de características.

c) Tempo. Gancho (2014) lembra que, na ficção, o tempo pode ser considerado em vários níveis. Um deles está 
relacionado à duração da obra, seja ela pode ser curta ou longa. Outro diz respeito à época em que a história se passa, ou seja, a época reproduzida na narrativa, o que pode diferir do tempo real de produção. A princípio, as obras fílmicas empregavam o tempo cronológico, isto é, o enredo linear seguia a ordem natural dos fatos. Porém, com o aprimoramento da linguagem cinematográfica, foi possível alterar a ordem natural dos acontecimentos. Assim, a ordem passou a ser "determinada pelo desejo ou pela imaginação do narrador ou das personagens" (GANCHO, 2014, p. 25), recorrendo-se muitas vezes à técnica do flashback, uma volta no tempo.

d) Espaço/ambiente. Ainda recorrendo ao trabalho de Gancho (2014), encontramos uma distinção entre espaço e ambiente. O primeiro é o lugar físico dos fatos da narrativa. Sobre ele, a professora afirma que "tem como funções principais situar as ações das personagens e estabelecer com eles uma interação, quer influenciando suas atitudes, pensamentos ou emoções, quer sofrendo eventuais transformações provocadas pelas personagens" (GANCHO, 2014, p. 27). Assim, a importância do espaço é evidenciada à medida que o ser fictício do enredo é influenciado por ele e, por sua vez, também o modifica.

e) Narrador. Diferente do autor, o narrador é uma criação ficcional que assume uma posição diante dos fatos narrados. Basicamente existem dois tipos de narrador: aquele que narra os fatos sem participar deles, denominado narrador observador; e, aquele que participa da história como qualquer outra personagem, o que justifica a classificação de narrador personagem. 
Para entendermos a estrutura de um curta-metragem, acreditamos ser útil o modelo de Michel Marie (1975), registrado na obra Ensaio sobre a análise fílmica, de Vanoye e Goliot-Lété (2014). O modelo apresenta parâmetros a serem considerados na primeira etapa de análise de um produto audiovisual, isto é, na fase de descrição dos elementos constituintes da obra:

1. Numeração do plano, duração em segundos ou número de fotogramas.

2. Elementos visuais apresentados.

3. Escala dos planos, incidência angular, profundidade de campo, objetiva utilizada.

4. Movimentos:

4.1 no campo, dos atores ou outros;

4.2 da câmera.

5. Raccords ou passagens de um plano a outro: olhares, movimentos, cortes, fusões ou escurecimentos, outros efeitos.

6. Trilha sonora: diálogos, ruídos, música; escala sonora; intensidade; transições sonoras, encavalamentos, continuidade/ruptura sonora.

7. Relações sons/imagens: sons in/off/ fora de campo; sons diegéticos ou extradiegéticos, sincronismo ou assincronismo entre imagens e sons (VANOYE; GOLIOT-LÉTÉ, 2014, p. 65-66).

No entanto, para identificar esses elementos em um vídeo, que vimos como essencial no nosso trabalho de intervenção da leitura dos curtas-metragens, por serem 
elementos que se integram na construção do sentido, da mensagem do curta, torna-se necessário um conhecimento básico da linguagem cinematográfica. Porém, como lembra Napolitano (2015), o professor para trabalhar filmes não precisa ser crítico profissional do cinema.

Para os principiantes neste tipo de gramática, provavelmente a obra de Alex Moletta (2009), Criação de curta-metragem em vídeo digital, possa auxiliá-los; pois, além de empregar uma linguagem bastante acessível, conceitua esses elementos à medida que aborda cada etapa de elaboração do audiovisual: roteiro, direção, fotografia, produção, montagem e finalização.

Juntamente com essa obra que trata da linguagem técnica podemos indicar o site Curta na Escola, sobre o qual falamos no início deste trabalho, em que vídeos curtos podem ser baixados ou usados on-line. Uma das vantagens é que esses vídeos pedagógicos disponibilizados são acompanhados por plano(s) de aula que orienta(m) o trabalho com diversos conteúdos a partir de um curta-metragem. Assim, após conhecer um pouco sobre a gramática da cinematografia é possível ampliar as possibilidades interpretativas de um filme.

Ainda sobre o livro de Moletta (2009), encontramos uma breve apresentação de vários elementos cinematográficos, inclusive daquele que é um intermediário entre o roteiro e a execução dele: o storyboard.

Por meio do storyboard pode-se conta uma história agregando fatores multimodais: o contexto em que se insere a história, a interação entre as personagens e a ideia de tempo. Elementos essenciais da narrativa bastante explorados hoje pelo cinema e que precisam ser lidos e compreendidos pelos alunos. 
O storyboard pode tornar-se uma etapa que antecede a escrita do texto, um elemento que favorece o planejamento do que vai ser dito na forma escrita, no caso da sala de aula; um guia visual narrando as principais cenas de uma história de forma progressiva. Esse guia pode permitir uma melhor preparação para a produção textual.

\section{Curta-metragem e sua aplicação no ensino e aprendizagem da leitura e da escrita}

Este subtópico tem como base teórica a visão da BNCC que dialoga com documentos e orientações curriculares produzidos nas últimas décadas. Este documento, no Eixo Leitura, um dos quatros que integram a BNCC de Língua Portuguesa, ratifica um conceito amplo de leitura, que não se limita ao texto escrito ou oral, mas também aos textos multissemióticos. Isto é, no contexto da BNCC, tanto o texto escrito, quanto as imagens estáticas ou em movimento, assim como o som são passíveis de leitura. Assim, contempla-se o que nos defendemos: um trabalho com a leitura a partir de curta-metragem:

O Eixo Leitura compreende as práticas de linguagem que decorrem da interação ativa do leitor/ouvinte/ espectador com os textos escritos, orais e multissemióticos e de sua interpretação, sendo exemplos as leituras para: fruição estética de textos e obras literárias; pesquisa e embasamento de trabalhos escolares e acadêmicos; realização de procedimentos; conhecimento, discussão 
e debate sobre temas sociais relevantes; sustentar a reivindicação de algo no contexto de atuação da vida pública; ter mais conhecimento que permita o desenvolvimento de projetos pessoais, dentre outras possibilidades (BRASIL, 2017, p. 69).

A leitura, neste contexto, é vista como uma atividade que constrói sentidos a partir da interação autor-texto-leitor, de modo que é necessário considerar o autor e o seu contexto de produção, assim como o texto e suas especificidades, além dos saberes e interesses do leitor.

Em relação à leitura de um texto multissemiótico, a exemplo de um curta-metragem, Moran (1995) indica alguns procedimentos didáticos que devem ser executados antes, durante e após a exibição do vídeo: a) informar aspectos gerais, tais como autor, duração, prêmios recebidos entre outros do vídeo; b) durante a exibição, anotar as cenas mais relevantes; se necessário, pausar o vídeo para fazer comentários, e observar as reações dos espectadores, e, por fim, c) retornar ao início do vídeo; rever as cenas mais significativas ou difíceis; passar quadro a quadro as imagens mais importantes; observar o som (música, efeitos, diálogos).

Depois desse processo de leitura que deve ser realizado pelos alunos e pelo professor de modo individual, Moran (2005) propõe algumas dinâmicas de análise do vídeo, de socialização das leituras individuais e suas reelaborações. Resumimos as propostas de análises de Moran a seguir: 
a) Análise em conjunto: conversar sobre as cenas mais importantes em que o professor deve posicionar-se depois dos alunos.

b) Análise globalizante: relato de aspectos positivos e negativos do vídeo, além das ideias principais e do que seria mudado. Após destacar coincidências e divergências, o professor faz a síntese final.

c) Leitura concentrada: após rever cena(s) marcante(s), questionar seus significados e aplicações para a vida, e o que se destaca mais (imagem, som ou palavra).

d) Análise "funcional": antes de exibir o vídeo, distribuir tarefas entre os alunos, tais como contar cenas, caracterizar personagens, anotar palavras-chave. Depois da exibição, registram-se no quadro as respostas, e professor e alunos completam as informações.

e) Análise da linguagem: expor a história contada e como ela é contada, bem como ideias e ideologias apresentadas.

f) Completar o vídeo: desenvolver um final para um vídeo que é exibido parcialmente e, após a exposição, comentá-lo.

g) Modificar o vídeo: editar um vídeo.

h) Videoprodução: narrar em vídeo um determinado assunto.

i) "Vídeo-espelho": observar e comentar o desempenho quando se é filmado pela câmera.

j)Videodramatização: a partir do vídeo assistido, dramatizar situações/personagens adaptadas à realidade dos alunos.

k) Comparar versões: comparar uma obra literária com sua adaptação cinematográfica, destacando pontos fortes e fracos em ambas as obras. 
Nas palavras de Indursky e Zinn (1985), a produção textual é desencadeada pela produção de leitura e se encerra ainda, com a leitura do sujeito-autor, o primeiro a ler o texto. As autoras esclarecem que "a leitura como suporte para a produção textual" possibilita ao indivíduo "exercer-se criticamente, interagir com o mundo, produzindo seus próprios textos" (1985, p. 27). Em outras palavras, a produção textual é antecedida pela produção de leitura, e esta

consiste no processo de interpretação, desenvolvido por um sujeito-leitor que, defrontando-se com um texto, analisa-o e questiona-o com o objetivo de processar seu significado, projetando sobre ele sua visão de mundo para estabelecer uma interação crítica com o texto (INDURSKY; ZINN, 1985, p. 24).

De acordo com as autoras, o aluno consegue ler criticamente quando há uma relação dinâmica com o professor, de modo que eles estabeleçam trocas entre si e se enriqueçam mutuamente, ou seja, tanto o aluno quanto o professor exercem alternadamente a função de sujeito diante do texto. Acreditamos que as dinâmicas de análise de vídeo na escola sugeridas por Moran possibilitam esse tipo de leitura.

Ainda de acordo com Indursky e Zinn (1985) essa produção de leitura é possível a partir de três etapas: leitura compreensiva, leitura interpretativa e leitura crítica. Estas etapas estão dispostas numa ordem de crescente 
complexidade. A primeira fase objetiva a apreensão do texto em sua globalidade, é o que Solé (2012) denomina de leitura para obter uma informação de caráter geral.

A próxima etapa, leitura interpretativa, por meio de um processo analítico, objetiva a descontextualização e recontextualização do texto, para revelar seus significados. É nesta fase que o texto é analisado em suas relações textuais, contextuais e intertextuais. No caso de um curta-metragem, é em relação aos elementos textuais que se fará uma análise da linguagem cinematográfica. É quando possível, segundo Vanoye e Goliot-Lété (2014), descrever os elementos constitutivos de um filme para em seguida reconstruí-lo. Essa leitura interpretativa tem o propósito de ler para aprender, logo, o leitor é levado "a se interrogar sobre o que lê, a estabelecer relações com o que já sabe, a rever os novos termos, a efetuar recapitulações e sínteses frequentes, a sublinhar, a anotar" (SOLÉ, 2012, p. 95).

Na última etapa do modelo proposto por Indursky e Zinn (1985, p. 24), a partir do conhecimento aprofundado sobre um texto é possível "estabelecer conclusões acerca da intencionalidade do texto e da ideologia que lhe subjaz". Consequentemente, o sujeito-leitor é capaz de posicionar-se criticamente sobre o texto, finalizando, desse modo, o ciclo de sua produção de leitura, o qual é pré-requisito básico para a produção textual.

A produção textual divide-se em planejamento e execução. Quanto ao planejamento, há quatro etapas: delimitação do tema; definição do posicionamento do sujeito-autor e de sua intencionalidade; seleção de ideias e argumentos; esquema com ideias e argumentos organizados. Na fase de execução, há a produção do texto-processo sob o enfoque do conteúdo e da forma; e, por último, a análise da 
produção textual de acordo com a organização das ideias, coerência e coesão dos recursos utilizados. E ao término, teremos o texto-produto. Nas palavras das autoras, a

[...] produção textual vem a ser a situação em que o sujeito-autor realiza a contextualização de idéias e argumentos que se inter-relacionam, num arranjo pessoal, apresentando organização e coerência, com o objetivo de produzir um texto que revele seu posicionamento (INDURSKY; ZINN, 1985, p. 26).

O texto deve ser entendido "como uma unidade significativa complexa, de natureza não apenas linguística, mas comunicacional, na qual intervêm elementos contextuais em sentido amplo" (INDURSKY; ZINN, 1985, p. 23).

Complementando essa visão, a BNCC de Língua Portuguesa, traz que o Eixo da Produção de Textos

compreende as práticas de linguagem relacionadas à interação e à autoria (individual ou coletiva) do texto escrito, oral e multissemiótico, com diferentes finalidades e projetos enunciativos como, por exemplo, construir um álbum de personagens famosas, de heróis/heroínas ou de vilões ou vilãs; [...] descrever, avaliar e recomendar (ou não) um game em uma resenha, gameplay ou vlog; [...] cobrir acontecimentos ou levantar 
dados relevantes para a comunidade em uma reportagem; expressar posição em uma carta de leitor ou artigo de opinião; denunciar situações de desrespeito aos direitos por meio de fotorreportagem, fotodenúncia, poema, lambe-lambe, microrroteiro, dentre outros (BRASIL, 2017, p. 74).

De acordo com o trecho acima, percebemos claramente a diversidade de gêneros discursivos/textuais e os multiletramentos contemplados pela BNCC. Nas circunstâncias atuais, tratar de leitura e produção textual sem considerar toda a diversidade e necessidade de uso das multissemioses é inadmissível. O ensino da leitura e da produção textual deve atender às necessidades sociais, as quais não são estáticas, mas reelaboradas constantemente.

Os multiletramentos requerem novas práticas de produção - seja a escrita, o áudio, o vídeo, o tratamento de imagem, a edição e a diagramação - bem como de análise crítica como receptor.

Diversos pesquisadores da área dos estudos linguísticos, dentre eles Dionísio (2011), Rojo e Barbosa (2015), vêm discutindo formas de utilização da modalidade visual nas práticas de escrita e utilizando nestes estudos, um novo conceito de modalidade de textos: os textos multimodais. Esses textos multimodais, conforme Rojo (2012) são compostos de muitas linguagens (ou modos, ou semioses) e exigem multiletramentos para fazer significar, isto é, requerem capacidades e práticas de compreensão e produção de cada uma dessas linguagens.

As práticas escolares educativas no contexto dos estudos linguísticos, devem proporcionar aos alunos a análise 
de textos que circulam socialmente, dentre estes, o audiovisual, o filme, o curta-metragem. A inclusão de vídeos em aulas de língua portuguesa pode possibilitar a ampliação dos limites da aprendizagem formal.

Além disso, a escola pode e deve orientar o aluno a fazer leituras eficientes, uma vez que não basta ver, é preciso saber assistir a filmes e vídeos, aprender a ler as partes e atingir uma compreensão global, do todo, como afirmam Vanoye e Goliot-Lété (2014) ao abordarem a análise fílmica. Portanto, é necessário ensinar os alunos a lerem, não apenas as palavras, mas também a lerem as imagens, os movimentos, os sons, os silêncios, as cores e os planos.

Como lembra Costa (2013), as imagens cada vez mais povoam a sociedade e ratificam a importância de educar o olhar e desenvolver a leitura de imagens. A autora explica que

a opção por uma educação que valoriza a educação pela e para a imagem não se faz em nome de uma ação pedagógica menos disciplinada ou mais espontaneísta, mas em busca de um entendimento mais afetivo do mundo e de uma comunicação mais abrangente e inclusiva (COSTA, p. 2013, p. 38).

Costa acrescenta, ainda, que a linguagem visual é mais inclusiva em relação à escrita, uma vez que não impõe barreiras intransponíveis entre as imagens e os observadores, tornando-se, dessa forma, mais igualitária e acessível. 
É importante reforçar que este trabalho não trata da valorização de uma ou outra modalidade da linguagem, mas da inclusão delas também na formação escolar do cidadão letrado. Como ratifica Dionisio (2011, p. 139), trata-se da harmonia visual estabelecida entre imagem e palavra, uma vez que "a multimodalidade é um traço constitutivo do discurso oral e escrito".

Além das semioses dos textos, devemos lembrar que os multiletramentos também incluem a multiculturalidade. A autora Rojo (2012) cita Canclini (2008), para quem "a produção atual se caracteriza por um processo de desterritorialização, de descoleção e de hibridação que permite que cada pessoa possa" inovar, principalmente a partir das novas tecnologias (apud ROJO, 2012, p. 16). Assim, nesse cenário globalizado, os limites que distanciam uma produção textual de outra - seja vídeo, poema, reportagem, etc. - são cada vez mais tênues.

É óbvio que o desenvolvimento da tecnologia tem contribuído com a expansão dos multiletramentos, tanto nas possibilidades de combinações de modalidades quanto na aproximação sociocultural entre grupos diversos. Contudo, é importante não esquecer, como afirma Masetto (2005), que a tecnologia é um instrumento que pode auxiliar no desenvolvimento da aprendizagem, no entanto, "ela somente terá importância ser for adequada para facilitar o alcance dos objetivos e se for eficiente para tanto" (MASETTO, 2005, p. 144). Acreditamos que é possível promover o desenvolvimento da aprendizagem em aulas de língua portuguesa por meio dessas tecnologias.

Como prática, damos como exemplo o estudo do vídeo Selfie com o gato. produzido na França, que tem como tema o selfie, como elemento de exibicionismo. Nesse estudo, 
procuramos explorar, de forma significativa e responsável, a linguagem e a narrativa de curta-metragem, desenvolvendo um trabalho de leitura e de escrita, considerando os elementos multimodais para a construção do sentido do texto.

\section{Proposta de leitura e produção textual a partir do curta Selfie Cat}

Apresentamos a seguir uma proposta, constituída por dois momentos pedagógicos, nos quais o curto Selfie Cat foi tomado como norteador de atividades, tentando construir uma concepção de curta-metragem como elemento de ensino e aprendizagem, defendendo sua viabilidade como recurso pedagógico multimodal.

O curta Selfie com o gato é muito dinâmico por apresentar uma multiplicidade de linguagens (visual, gestual, sonora, cinética) e, também, por apresentar um tema presente no cotidiano dos adolescentes - o que aumenta as possibilidades de ele ser mais bem aceito pelos alunos do Ensino Fundamental. Este curta foi produzido em 2016, dirigido por Elsa Divet, Emiline Bernard e Geoffrey Assie e pertencente ao gênero animação comédia. Narra-se neste curta a situação em que uma menina tenta tirar uma selfie com seu gato para disputar popularidade na Internet. Antes de iniciar a exibição do curta-metragem é bom expor essas informações sobre o vídeo, como propõe Moran (1995).

Este curta, como qualquer outro texto, é passível de leitura. Sendo assim, pode-se sondar os níveis de leitura realizada pelos alunos, bem como realizar uma produção textual a partir da leitura do vídeo Selfie com o gato, de 
duas formas: por meio de uma retextualização e/ou da criação de uma nova história com um texto multimodal, por exemplo.

Após a exibição do curta, deve-se investigar as dificuldades apresentadas pelos participantes ao que se refere à leitura desse texto multimodal. Em seguida, propor a retextualização do texto multimodal, por meio da modalidade verbal escrita, ou seja, solicitando que o aluno relate o enredo do vídeo com detalhes.

$\mathrm{Na}$ etapa seguinte, para aprimorar a leitura desse gênero, é pertinente realizar atividades que tenham como objetivo conduzir o aluno a uma leitura mais reflexiva da linguagem do curta, isto é, da linguagem cinematografia e dos elementos para a realização do vídeo - com perguntas sobre planos, ângulos e movimentos de câmera, os tipos de linguagem, som -, com o intuito de trabalhar o texto multimodal.

Para isso, nas próprias atividades, os termos do universo da linguagem cinematográfica devem ser explicados, bem como sobre os elementos da narrativa. Nessas atividades, questões de compreensão da narrativa, por exemplo, personagens, espaço, tempo, ações, desfecho também são importantes.

Após a realização das atividades e discussões realizadas a partir da sua execução, deve-se solicitar que o aluno acrescente ao seu texto (relato) novas informações, coletadas das atividades feitas. Esta aplicação tem por finalidade verificar se a leitura inicial realizada pelos alunos foi modificada e ampliada com a inclusão de novos elementos, depois das atividades e discussões realizadas.

Uma das funções mais árduas dos professores de português é conduzir o aluno a reescrever seu texto ou 
aprimorá-lo. Os alunos ainda não veem a importância dessa ação e muitos professores terminam cedendo e não realizam esta prática, quebrando assim uma etapa importante do processo de aprendizagem da escrita.

O vídeo é um texto com elementos que precisam ser estudados na sala de aula. Segundo Silva (2014b, p. 136137), "quando lidamos com as chamadas linguagens complexas, devemos considerar as relações entre os códigos verbais, visuais e sonoros para a composição da mensagem que se deseja transmitir". Logo, concordamos que "a alfabetização dos espectadores na gramática cinematográfica é o melhor caminho para constituir um público menos passivo e mais exigente" (COSTA, 2013, p. 105).

\section{Criando textos multimodais}

Para dar continuidade ao estudo, apresentamos como sugestão a produção de textos multimodais, partindo-se de um enredo. Assim, amplia-se a concepção escolar de texto e de leitura, propiciando aos alunos a construção do sentido de um texto multimodal, testando a criatividade narrativa dos alunos e as habilidades com os recursos para contar uma história por meio de imagens ou palavras e imagens, construindo uma rede intertextual que se apoia na prática da leitura e da escrita.

Isto tudo após a exposição sobre o que é um enredo, sobre a necessidade de se fazer um relato sobre os fatos vividos pelas personagens e ordená-los em uma sequência lógica e temporal; usando de alguns elementos linguísticos, como por exemplo, o uso de verbos de ação que indicam a movimentação das personagens no tempo e no espaço. Geralmente, o enredo está centrado num conflito, 
que responsável pelo nível de tensão da narrativa. E, depois, em um outro momento, criar um storyboard, a partir das indicações sugeridas no vídeo Como criar storyboard (CARVALHO, 2016), buscando levar o aluno a entender o processo de criação das cenas ou, simplesmente, dos quadros que ganham vida, quando se agregam outras linguagens, movimentos e som, cor e efeitos.

Pode-se iniciar esta etapa de produção textual distribuindo notícias/acontecimentos sobre selfie, divulgados na internet, dando continuidade ao assunto do curta Selfie Cat, para que os alunos produzam um enredo e, logo, em seguida um storyboard com a seguinte temática "Consequências de selfies", realizando, assim, o gênero multimodal, que pode ainda ser transformado em um curta, caso haja recursos.

Embora tenhamos sintetizado várias etapas importantíssimas na produção de um audiovisual, como por exemplo, o roteiro, o qual não trabalhamos, esta proposta pode levar a uma compreensão da linguagem de um vídeo, da sua realização e produção.

\section{Considerações finais}

Nessa proposta de estudo, partimos de uma prática corriqueira que é assistir a vídeos curtos. Esta atividade é habitual, se considerarmos a frequência com que as crianças e adolescentes assistem a vídeos; entretanto, mostra-se complexa quando se intensifica a necessidade de ler tais textos e não simplesmente vê-los. E, mais ainda, quando se impõe a necessidade de produção textos multimodais.

Os pontos positivos quando à leitura, na execução dessa proposta de curtas-metragens, é levar o aluno não 
só a ver um vídeo, mas também a entender a linguagem usada pelo texto multimodal, pois como lembra Silva (2014a), todos os recursos utilizados e colaborados para o enriquecimento da mensagem que se deseja passar.

Destacamos que os professores não precisam ser profissionais da área cinematográfica, mas alguém que acredita no potencial dos curtas-metragens e têm interesse em conhecer mais sobre esse texto multimodal, para poder melhor utilizá-lo em sala de aula.

Por fim, acreditamos no poder comunicativo, interativo e incentivador do curta; e, em professores engajados e capazes de conduzir os alunos a saberem atribuir sentidos a mensagens com múltiplas formas de linguagens, bem como a produzirem textos multimodais.

\section{Referências}

ALCÂNTARA, Jean C. D. Curta-metragem: gênero discursivo propiciador de práticas multiletradas. 138 p. Dissertação (Mestrado em Estudos de Linguagem) Instituto de Linguagens, Universidade Federal de Mato Grosso, Cuiabá-MT, 2014.

ARENAANIMATION. Twisted. YouTube, 13 dez. 2017. Disponível em: <https://www.youtube.com/watch?v=J_daotPZ2Kk>. Acesso em: 10 jun. 2017.

ARTFX. Selfie Cat. YouTube, 6 jul. 2016. Disponível em: <https://www.youtube.com/watch?v=LEL81DVIHMk>. Acesso em: 15 mar. 2017. 
AUMONT, Jacques; MARIE, Michel. Dicionário teórico e crítico de cinema. Trad. Eloisa Araújo Ribeiro. 5. ed. $3^{\text {a }}$ reimpressão. Campinas, São Paulo: Papirus, 2015.

BERNARDET, Jean-Claude. O que é cinema. $14^{\mathrm{a}}$ reimpressão. São Paulo: Brasiliense, 2004. (Coleção Primeiros Passos; 9)

BRASIL. Ministério da Educação. Base Nacional Comum Curricular. MEC. Brasília, DF, 2017.

. Secretaria de Educação Fundamental. Parâmetros curriculares nacionais: terceiro e quarto ciclos do ensino fundamental: introdução aos parâmetros curriculares nacionais. Brasília: MEC/SEF, 1998a. 174 p.

. Secretaria de Educação Fundamental. Parâmetros curriculares nacionais: terceiro e quarto ciclos do ensino fundamental: língua portuguesa. Brasília: MEC/SEF, 1998b. 106 p.

CARVALHO, Vitor. Como criar storyboard. YouTube, 5 ago. 2016. Disponível em: <https://www.youtube.com/ watch?v=RZcuGbbWNaQ>. Acesso em: 17 nov. 2017.

COSTA, Cristina. Educação, imagem e mídias. 2. ed. São Paulo: Cortez, 2013. (Coleção aprender e ensinar com textos, v. 12/ coord. geral Ligia Chiappini)

DIONISIO, Angela P. Gêneros textuais e multimodalidade. In: KARWOSKI, Acir Mário; GAYDECZKA, Beatriz; BRITO, Karim S. (Orgs.). Gêneros textuais: reflexões e ensino. 4. ed. São Paulo: Parábola, 2011. 
GANCHO, Cândida V. Como analisar narrativas. 9 ed., $8^{\mathrm{a}}$ impressão. São Paulo: Ática, 2014. (Princípios; 207)

HOUAISS, A.; VILLAR, M. S. Dicionário Houaiss de Língua Portuguesa. Elaborado pelo Instituto Antônio Houaiss de Lexicografia e Banco de Dados da Língua Portuguesa S/C Ltda. Rio de Janeiro: Objetiva, 2009.

INDURSKY, Freda; ZINN, Maria Alice K. Leitura como suporte para a produção textual. In: Leitura: teoria \& prática. $\mathrm{n}^{\circ}$ 05, Campinas-SP: Mercado Aberto/ABL, 1985. p. 22-36.

$\mathrm{KOCH}$, Ingedore V.; ELIAS, Vanda M. Ler e compreender: os sentidos do texto. 3. ed., $11^{a}$ impressão. São Paulo: Contexto, 2015.

MASETTO, Marcos T. Mediação pedagógica e o uso da tecnologia. In: MORAN, José M.; MASETTO, Marcos T.; BEHRENS, Marilda A. (Orgs.). Novas tecnologias e mediação pedagógica. 9 ed. Campinas, SP: Papirus, 2005.

MESQUITA, Samira N. O enredo. 4. ed., $8^{a}$ impressão. São Paulo: Ática, 2006. (Princípios; 36)

MOLETTA, Alex. Criação de curta-metragem em vídeo digital: uma proposta para produções de baixo custo. 3 . ed. São Paulo: Summus, 2009.

MORAN, José M.; Ensino e aprendizagem inovadores com tecnologias audiovisuais e telemáticas. In: MORAN, José M.; MASETTO, Marcos T.; BEHRENS, Marilda A. Novas tecnologias e mediação pedagógica. 9. ed. Campinas, SP: Papirus, 2005. p. 11-65. (Coleção Papirus Educação) 
. O vídeo na sala de aula. In: Comunicação \&

Educação. São Paulo, ECA-Ed. Moderna, [2]: 27 a 35, jan./ abr. de 1995.

NAPOLITANO, Marcos. Como usar o cinema na sala de aula. 5. ed., $2^{\mathrm{a}}$ reimp. São Paulo: Contexto, 2015.

RIBEIRO, Carla.G. O curta-metragem como recurso didático para aula de E/LE. 2013. 146 p. Dissertação (Mestrado em Linguagem) - Faculdade de Letras, Universidade de Coimbra, Coimbra.

RIBEIRO, Ana E. Textos multimodais: leitura e produção. Paulo: Parábola, 2016. (Linguagens e tecnologias; 4)

ROJO, Roxane H. R. Pedagogia dos multiletramentos: diversidade cultural e de linguagem na escola. In:

MOURA, Eduardo. (Orgs.). Multiletramentos na escola. São Paulo: Parábola, 2012. p. 11-31. (Estratégias de ensino; 29)

.; BARBOSA, Jacqueline P. Hipermodernidade, multiletramentos e gêneros discursivos. São Paulo: Parábola, 2015. (Estratégias de ensino; 51)

SILVA, Salete T. A. A linguagem cinematográfica na escola: uma leitura d'O Rei Leão. In: CITELLI, Adilson (Coord.). Outras linguagens na escola: publicidade, cinema e TV, rádio, jogos, informática. 5. ed. São Paulo: Cortez, 2014a. (Coleção aprender e ensinar com textos, v. 6) p. 89-120.

_. Desenho animado e educação. In: CITELLI, Adilson (Coord.). Outras linguagens na escola: publicidade, 
cinema e TV, rádio, jogos, informática. 5. ed. São Paulo: Cortez, 2014b. (Coleção aprender e ensinar com textos, v. 6) p. 121-147.

SOLÉ, Isabel. Estratégias de leitura. Trad. Claudia Schilling. 6. ed. $1^{\text {a }}$ reimpressão. Porto Alegre: Penso, 2012.

VANOYE, Francis; GOLIOT-LÉTÉ, Anne. Ensaio sobre a análise fílmica. Trad. Marina Appenzeller. 7. ed., $3^{\mathrm{a}}$ reimpressão. Campinas, SP: Papirus, 2014. 